\title{
META ANALYSIS: THE EFFECT OF HIGH-INTENSITY INTERVAL TRAINING ON LOW DENSITY LIPOPROTEIN LEVEL IN PATIENTS WITH TYPE 2 DIABETES MELITUS
}

\author{
Sela Putri Adelita1), Eti Poncorini Pamungkasari²), Bhisma Murti1) \\ ${ }^{1)}$ Masters Program in Public Health, Universitas Sebelas Maret, \\ 2)Departement of Public Health, Faculty of Medicine, Universitas Sebelas Maret
}

\begin{abstract}
Background: High intensity interval training (HIIT) is a protocol of short work intervals of vigorous to high intensity interspersed with active or passive (cessation of movement) recovery periods. HIIT has been employed since the mid-2oth century to improve athletic exercise performance. Regular exercise reduces elevated low-density lipoprotein (LDL), atherosclerosis formation, and risk factors of cardiovascular disease (CVD). This study aimed to examine the effect of high-intensity interval training on low density lipoprotein level in patients with type 2 diabetes mellitus (DM).

Subjects and Method: This was meta-analysis and systematic review. The study was conducted by search published article from year 2010 to 2020 in PubMed, Science Direct, Research Gate, and Google Scholar databases. The inclusion criteria were full text, using randomized controlled trial study design, high-intensity interval training intervention, and reporting mean and standard deviation. Study subjects were type 2 DM patients aged 25-65 years. The study outcome was LDL reduction. The articles were analyzed by PRISMA flow chart and Revman $5 \cdot 3$.

Results: 7 studies from America, Europe, Australia, and Asia showed that high intensity interval training reduced LDL level in type 2 DM patients (Mean Difference $=-0.06$; 95\% CI $=1.32$ to $0.47 ; \mathrm{p}<0.001)$ with $\mathrm{I}_{2}=92 \%(\mathrm{p}<0.93)$.
\end{abstract}

Conclusion: High-intensity interval training reduces LDL level in type 2 DM patients.

Keywords: high-intensity interval training, low density lipoprotein

\section{Correspondence:}

Sela Putri Adelita. Masters Program in Public Health, Universitas Sebelas Maret. Jl. Ir. Sutami 36A, Surakarta 57126, Central Java. Email: Selaadelita558@gmail.com. Mobile: 085357117517.

The $7^{\text {th }}$ International Conference on Public Health

Solo, Indonesia, November 18-19, 2020 410 https://doi.org/10.26911/the7thicph.05.42 